\title{
Construction of DGLA producing cell factory by genetic modification of Mucor circinelloides
}

\author{
Md. Ahsanul Kabir Khan ${ }^{1 \dagger}$, Junhuan Yang ${ }^{1,2+}$, Syed Ammar Hussain ${ }^{1}$, Huaiyuan Zhang ${ }^{1}$, Li Liang ${ }^{3}$, \\ Victoriano Garre $2^{2^{*}}$ and Yuanda Song ${ }^{1 *}$
}

\begin{abstract}
Background: Dihomo-gamma linolenic acid (DGLA, 20:3, n-6) is the elongated product of Gamma linolenic acid (GLA, 18:3, n-6) catalyzed by the enzyme delta-6 elongase (D6E) or gamma linolenic acid elongase (GLELO). Construction of engineered oleaginous microbes have been attracting significant interest to produce DGLA because of its nutritional value and medicinal applications. Mucor circinelloides is a GLA producing filamentous fungus which can be a useful tool to produce DGLA. We have, therefore, overexpressed the D6E (GLELO) gene in this fungus to construct DGLA producing cell factory.
\end{abstract}

Result: To produce DGLA in M. circinelloides, homologous overexpression of D6E (GLELO) gene was analyzed. When the gene was overexpressed in M. circinelloides CBS277.49, up to 5.72\% DGLA was produced in this strain.

Conclusion: To our knowledge, this is the first report describing the overexpression of D6E (GLELO) gene in M. circinelloides to construct DGLA producing cell factory. A new scope for further research has been established by this work for improved production of DGLA in this fungus, specifically in its high lipid-producing strain, WJ11.

Keywords: Delta-6 elongase, DGLA production, Homologous overexpression, Mucor circinelloides

\section{Introduction}

Polyunsaturated fatty acids (PUFAs) are attracting significant interest because they have important roles in human health and nutrition [1]. Mammals, including humans, can synthesize saturated fatty acids (SAFA) and monounsaturated fatty acids (MUFA) but cannot synthesize de novo omega- 6 or omega-3 polyunsaturated fatty acids (PUFA) which are linoleic acid (LA, 18:2, n-6) and $\alpha$-linolenic acid (ALA, 18:3, n-3) respectively. Therefore, these PUFA are essential fatty acids (EFAs) for human health and must be obtained from the diet $[1,2]$. LA and

\footnotetext{
*Correspondence: vgarre@um.es; ysong@sdut.edu.cn

${ }^{\dagger}$ Md. Ahsanul Kabir Khan and Junhuan Yang contributed equally to this work and are considered as first author

${ }^{1}$ Colin Ratledge Center for Microbial Lipids, School of Agricultural Engineering and Food Science, Shandong University of Technology, Zibo 255000, Shandong, People's Republic of China

${ }^{2}$ Departmento de Genética y Microbiología (Unidad Asociada al Instituto de Química Física Rocasolano, Consejo Superior de Investigaciones Científicas), Facultad de Biología, Universidad de Murcia, 30100 Murcia, Spain

Full list of author information is available at the end of the article
}

ALA are metabolised to Docosapentaenoic acid (DPA, 22:5, n-6) and Docosahexaenoic acid (DHA, 22:5, n-3) respectively in a series of reactions catalyzed by the same sets of enzymes [3]. But several diseases such as obesity, hypertension, diabetes mellitus, coronary heart disease, schizophrenia, Alzheimer's disease, atherosclerosis, and cancer can alter the metabolism of essential fatty acids (EFAs). This indicated that EFAs and their derivatives have various biological activities and appear to be involved in a number of physiological and pathological reactions [4].

$\mathrm{A} \mathrm{C}_{20}$ PUFA with three double bonds named dihomogamma linolenic acid (DGLA, 20:3, n-6) is the elongated product of Gamma linolenic acid (GLA, 18:3, n-6) catalyzed by the enzyme $\Delta 6$ elongase [1]. Recently DGLA has attracted significant biological interest becasue it undergoes oxidative metabolism by cyclooxygenases and lipoxygenases to produce anti-inflammatory eicosanoids (prostaglandins of series 1 and leukotrienes of series 3) [5]. DGLA can also be converted to arachidonic acid (AA, 20:4, n-6) by the action of the enzyme delta-5 
desaturase. AA forms the precursor of 2 series of prostaglandins, thromboxanes and the 4 series of leukotrienes [6].

Some fungi, microalgae and bacteria can accumulate lipid more than $20 \%$ of their cell dry weight (CDW) hence they are called oleaginous microorganisms [7]. Mucor circinelloides has been extensively investigated for GLA production since the 1980s [8-10]. Among oleaginous filamentous fungi, it has been considered as an important model organism for lipid accumulation studies due to its ability to produce an oil rich in GLA that may have special effects for the treatment of premenstrual tension, atopic dermatitis and some other diseases and also due to the availability of genome data and genetic tools [7].

Because of nutritional value and medicinal applications many groups are constructing engineered DGLA producing microbes such as recombinant Aspergillus oryzae, Saccharomyces cerevisiae and Mortierella alpina but all of these strains have some limitations such as lower DGLA producing and problems to separate DGLA from other fatty acids $[1,11,12]$. M. alpina can accumulate lipids up to $50 \%$ of its dry weight with high amount of arachidonic acid (AA, 20:4, n-6) [13-16]. Some of its essential genes for lipid synthesis have been cloned and partially characterized, and several biochemical reactions have been studied in detail [17]. Delta 6-elongase enzyme is responsible for elongation of GLA $(18: 3 n-6)$ to dihomo-gamma-linolenic acid (20:3 n-6), hence the gene is known as gamma linolenic acid elongase (GLELO) gene [18]. M. circinelloides is a GLA producing filamentous fungus which can be a useful tool to produce DGLA. In this experiment we have cloned $D 6 E$ (GLELO) gene from $M$. alpina and attempted to construct a DGLA producing cell factory by genetic recombination in M. circinelloides.

\section{Results}

\section{Generation of D6E-Overexpressing strains of $M$.}

\section{circinelloides by genetic engineering}

Based on the genomic data of Mortierella alpina, we found the gene encoding for D6E (GLELO) (Genebank accession number AF206662) which is 957 bp long. To overexpress the target gene, the plasmid pMAT1552gene that contains the target gene coding region under the control of the strong zrt1 promoter of $M$. circinelloides [8] was generated (Fig. 1). The target gene-overexpressing plasmids, pMAT1552-GLELO and the empty plasmids pMAT1552 was transformed into the uridine auxotrophic strain, pleu-MU402 and selection of the colonies were carried out as described by Rodr' 1 guezFr'ometa [19].

Integration of the target genes into the genome of overexpression transformants, were confirmed by PCR analysis. Amplification was carried out using a primer

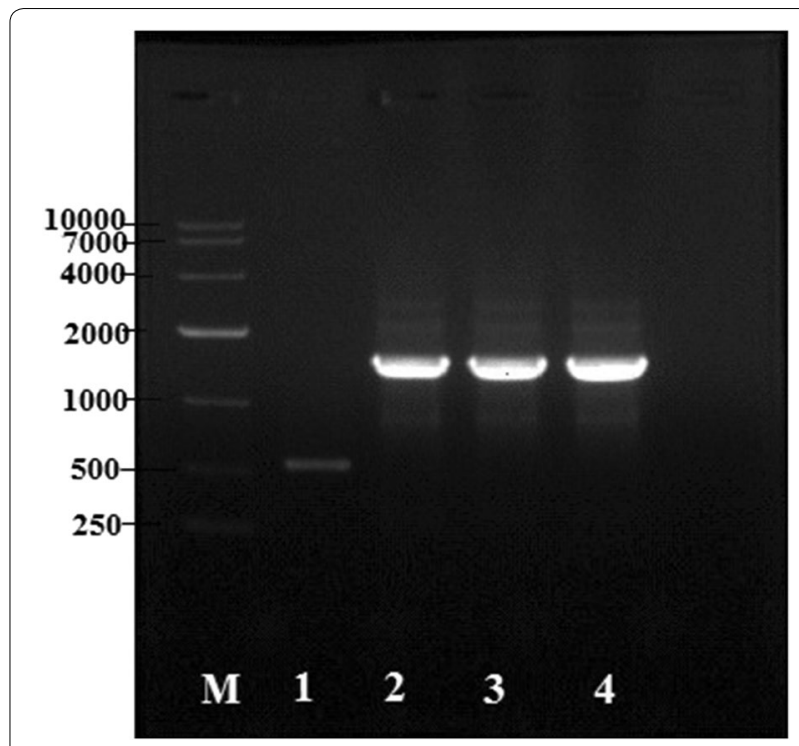

Fig. 1 PCR amplification of genome of control and recombinant strains with the primers $1552-\mathrm{F} / \mathrm{R}$. Lane 1 representing the control strain Mc-1552 and 2, 3, 4 showing the presence of D6E gene in recombinant strains $\mathrm{Mc}$-D6E, Mc-D6E- 1 and $\mathrm{Mc}$-D6E- 2 respectively

pair 1552-F/R (Additional file 1: Table S1) that amplified the target gene and $557 \mathrm{bp}$ sequences of the plasmid pMAT1552. The PCR product fragments for each transformants was 1514 bp as expected, in these corresponding transformants genome, whereas $557 \mathrm{bp}$ fragments was amplified in the control strain Mc-1552 (Fig. 1). PCR amplification results confirmed that the target genes had been integrated into the genome of the fungus in these transformants. For overexpression strain, three transformants were selected, named Mc-D6E, Mc-D6E-1, McD6E-2 and the control transformant that was named as Mc-1552. Additional screening was carried out (data was not mentioned) and only one strain (Mc-D6E) which produced maximum amount of lipid and DGLA, was selected for further experiments.

\section{Cell growth and lipid accumulation in recombinant $M$. circinelloides}

The concentrations of ammonium and glucose in culture medium, cell dry weight (CDW), and lipid accumulation of Mc-1552 and Mc-D6E during growth were determined and shown in Fig. 2. In general, the recombinant strain showed a similar and typical growth profile as the control strain. Ammonium was used up at approx. $24 \mathrm{~h}$ by Mc-D6E but it was utilized more rapidly by the control strain Mc-1552 and glucose remained in excess during the entire bioprocess (Fig. 2a, b). CDW increased rapidly after $9 \mathrm{~h}$ of cultivation, and then slowed down after nitrogen exhaustion (Fig. 2c). Immediately after nitrogen 

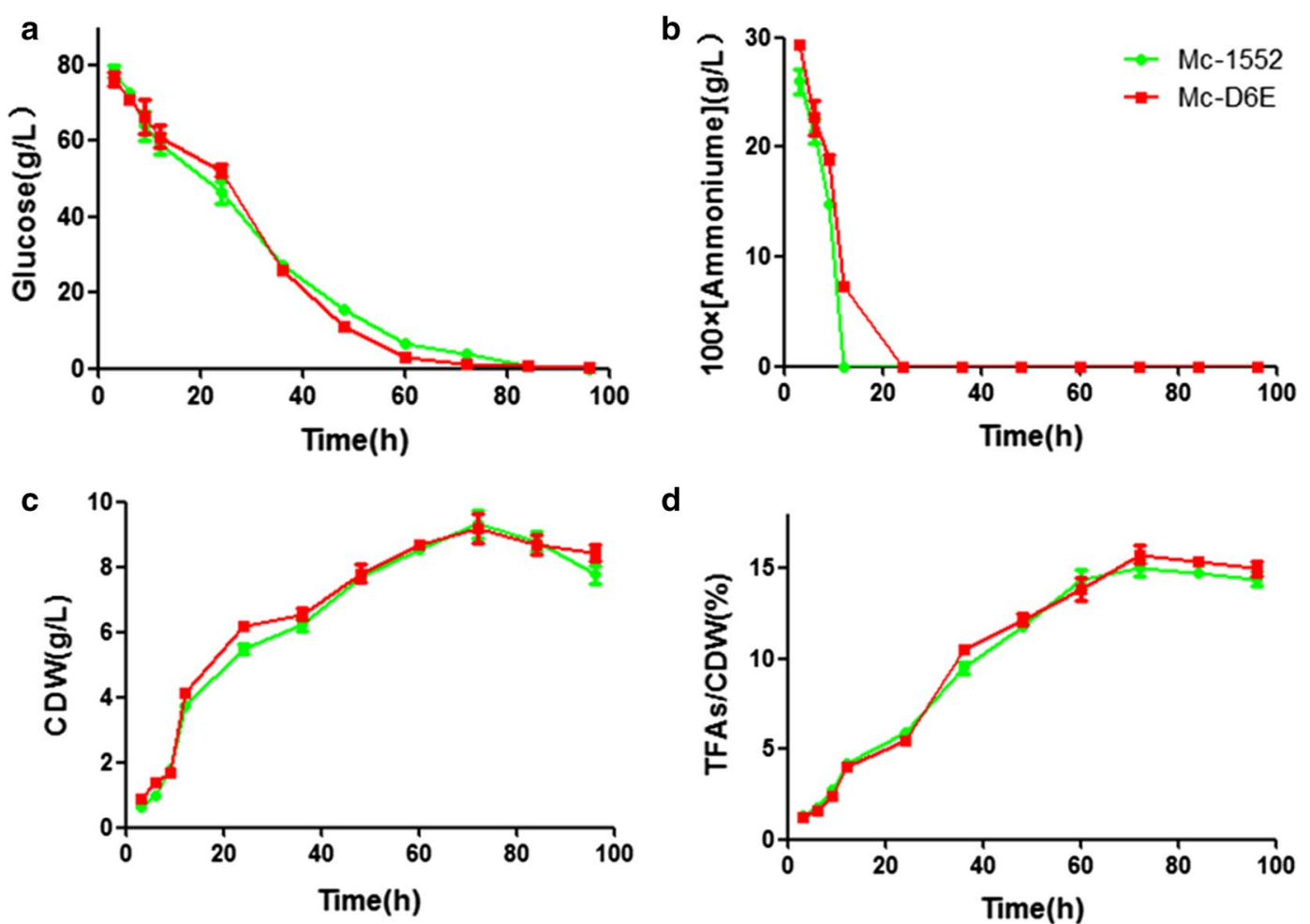

Fig. 2 Cell growth and lipid accumulation of D6E overexpressing strains. Recombinant Mc-D6E and control strain Mc-1552 cultures were grown in $1.5 \mathrm{~L}$ modified $\mathrm{K} \& \mathrm{R}$ medium and $\mathbf{a}$ glucose concentration, $\mathbf{b}$ ammonium concentration, $\mathbf{c}$ cell dry weight (CDW), and $\mathbf{d}$ Lipid content were measured. Samples from the fermenter were taken at the indicated times. The values were mean of three biological replicates. Error bars represent the standard error of the mean

depletion from the growth medium, the fungi started to accumulate lipids; from $24 \mathrm{~h}$, the total fatty acids (TFAs) content increased rapidly, reached at its peak at $72 \mathrm{~h}$ and then slowed down (Fig. 2d).

\section{DGLA accumulation in D6E (GLELO) overexpressing strains}

The fatty acid composition in D6E (GLELO) overexpressing strains were presented in Table 1 and cell dry weight (CDW), total fatty acids (TFAs) and DGLA yields were mentioned in Table 2. In the transformants, DGLA production started at $24 \mathrm{~h}$, and at $48 \mathrm{~h}$ its content reached at almost $5 \%$. The highest percentage $(5.72 \%)$ of DGLA was measured at $60 \mathrm{~h}$ (Table 1). However the yield was maximum at $72 \mathrm{~h}$ which was $74.61 \mathrm{mg} / \mathrm{l}$ as it is corresponding to the TFAs content (Table 2). In these recombinant fungi there were little changes in other fatty acid contents compared with the control strain (Table 1).

\section{Expression levels of $D 6 E$ (GLELO) gene in the overexpressing strains}

Real-time quantitative PCR were carried out to analyze the mRNA level of D6E (GLELO) in the selected overexpression strains at $3,24,48$ and $72 \mathrm{~h}$ of growth in $2 \mathrm{l}$ fermenter with K\&R medium (Fig. 3). The mRNA expression level of Mc-D6E was considered as 1 at $3 \mathrm{~h}$ and by comparing with this value the expression level was increased respectively by $5.45,3.6$ and 2.8 fold at 24,48 and $72 \mathrm{~h}$ in overexpressing strains. Although it increased quickly from 3 to $24 \mathrm{~h}$ but there was a decreasing trend with the incubation time after $24 \mathrm{~h}$. The fact that D6E mRNA was maintained at elevated levels throughout the whole culture time confirmed that it was overexpressed in the recombinant strains.

\section{Discussion}

Very-long-chain polyunsaturated fatty acid (VLCPUFA) production in transgenic organisms is a process which can further enhance the production of desired products [20]. The oleaginous fungus, M. circinelloides, is attracting considerable interest as it produces oil rich in Gamma linolenic acid. On the other hand M. alpina produce both ARA and EPA. But in all other aspects, both fungi share similar properties and phenotype (filamentous) [3]. Fatty acid elongase, GLELO of M. alpina ATCC 32221, is reported to convert 18-carbon PUFAs to the corresponding 20-carbon ones [21]. Conversion 
Table 1 The fatty acid composition in D6E (GLELO) overexpressing strains

\begin{tabular}{|c|c|c|c|c|c|c|}
\hline \multirow{2}{*}{$\begin{array}{l}\text { Time } \\
\text { Hour }\end{array}$} & \multicolumn{6}{|c|}{ Fatty acid composition (relative $\%, w / w$ ) } \\
\hline & $C(16: 0)$ & $C(18: 0)$ & $\begin{array}{l}C(18: 1) \\
O A \%\end{array}$ & $\begin{array}{l}\text { C(18:2) } \\
\text { LA \% }\end{array}$ & $\begin{array}{l}\text { C(18:3) } \\
\text { GLA \% }\end{array}$ & $\begin{array}{l}C(20: 3) \\
\text { DGLA \% }\end{array}$ \\
\hline \multicolumn{7}{|c|}{ Mc-1552 } \\
\hline $12 \mathrm{~h}$ & - & - & $32.38 \pm 1.33$ & $30.87 \pm 0.96$ & $36.75 \pm 0.88$ & - \\
\hline $24 \mathrm{~h}$ & $29.10 \pm 0.75$ & $7.84 \pm 0.58$ & $20.43 \pm 0.44$ & $16.50 \pm 0.67$ & $26.13 \pm 0.37$ & - \\
\hline $36 \mathrm{~h}$ & $29.91 \pm 0.52$ & $7.60 \pm 0.27$ & $22.57 \pm 0.11$ & $14.39 \pm 0.38$ & $25.53 \pm 0.23$ & - \\
\hline $48 \mathrm{~h}$ & $22.23 \pm 0.64$ & $4.32 \pm 0.44$ & $26.68 \pm 0.32$ & $16.56 \pm 0.25$ & $30.21 \pm 0.10$ & - \\
\hline $60 \mathrm{~h}$ & $24.72 \pm 0.07$ & $3.70 \pm 0.15$ & $25.85 \pm 0.08$ & $15.78 \pm 0.05$ & $29.95 \pm 0.05$ & - \\
\hline $72 \mathrm{~h}$ & $24.92 \pm 0.25$ & $2.71 \pm 0.32$ & $26.09 \pm 0.22$ & $15.68 \pm 0.30$ & $30.60 \pm 0.20$ & - \\
\hline \multicolumn{7}{|c|}{ Mc-D6E } \\
\hline $12 \mathrm{~h}$ & $33.08 \pm 1.78$ & $7.56 \pm 2.03$ & $16.70 \pm 1.1$ & $18.44 \pm 1.23$ & $24.19 \pm 0.86$ & - \\
\hline $24 \mathrm{~h}$ & $32.45 \pm 0.52$ & $6.59 \pm 0.88$ & $18.28 \pm 0.93$ & $17.57 \pm 1.10$ & $23.37 \pm 0.68$ & $1.72 \pm 0.88$ \\
\hline $36 \mathrm{~h}$ & $25.95 \pm 1.98$ & $3.89 \pm 0.91$ & $26.92 \pm 1.43$ & $15.35 \pm 0.93$ & $24.20 \pm 1.32$ & $3.66 \pm 1.52$ \\
\hline $48 \mathrm{~h}$ & $26.87 \pm 0.08$ & $4.79 \pm 0.26$ & $21.16 \pm 0.00$ & $16.02 \pm 0.33$ & $26.19 \pm 0.07$ & $4.94 \pm 0.07$ \\
\hline $60 \mathrm{~h}$ & $24.99 \pm 0.72$ & $4.07 \pm 0.32$ & $24.60 \pm 0.44$ & $15.48 \pm 0.50$ & $26.39 \pm 0.64$ & $5.72 \pm 0.77$ \\
\hline $72 \mathrm{~h}$ & $27.28 \pm 0.04$ & $9.43 \pm 0.61$ & $21.48 \pm 0.10$ & $14.48 \pm 0.67$ & $21.59 \pm 0.45$ & $5.16 \pm 0.13$ \\
\hline
\end{tabular}

The values represent the mean $\pm S D$ of three independent experiments

Table 2 The cell dry weight (CDW), total fatty acids (TFA) and DGLA yields in D6E (GLELO) overexpressing strains

\begin{tabular}{lllr}
\hline $\begin{array}{l}\text { Cultivation time } \\
\text { (hour) }\end{array}$ & CDW (g/l) & TFA (g/l) & DGLA (mg/l) \\
\hline $12 \mathrm{~h}$ & $4.15 \pm 0.68$ & $0.17 \pm 0.55$ & \multicolumn{1}{l}{-} \\
$24 \mathrm{~h}$ & $6.20 \pm 0.43$ & $0.34 \pm 0.67$ & $5.81 \pm 0.83$ \\
$36 \mathrm{~h}$ & $6.54 \pm 1.27$ & $0.69 \pm 1.77$ & $25.13 \pm 1.68$ \\
$48 \mathrm{~h}$ & $7.80 \pm 0.05$ & $0.95 \pm 0.04$ & $46.81 \pm 0.09$ \\
$60 \mathrm{~h}$ & $8.67 \pm 0.89$ & $1.20 \pm 0.66$ & $68.69 \pm 0.59$ \\
$72 \mathrm{~h}$ & $9.18 \pm 0.23$ & $1.45 \pm 0.33$ & $74.61 \pm 0.19$ \\
\hline
\end{tabular}

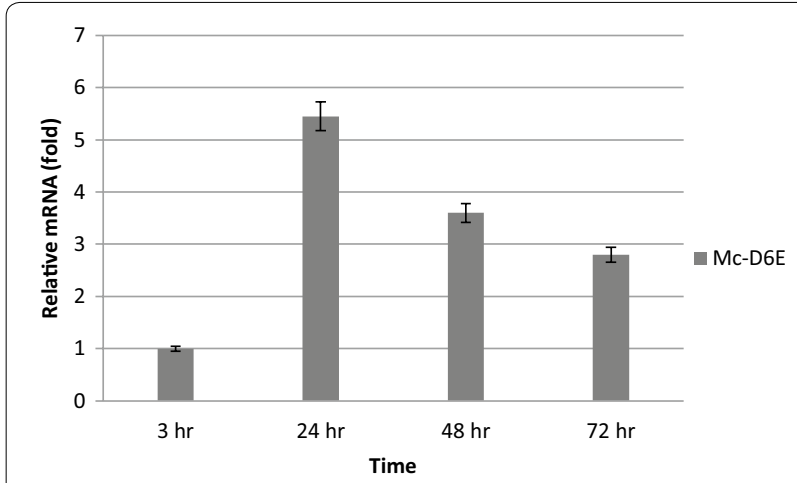

Fig. 3 Determination of expression levels of D6E (GLELO) genes by RT-qPCR in the overexpressing strains of GLA to DGLA is one step process catalyzed by Delta 6-elongase enzyme [3] encoded by $D 6 E$ gene which we have cloned from M. alpina and expressed in M. circinelloides. Previously Delta5-Desaturase-defective mutant of M. alpina 1S-4 exhibited increased DGLA accumulation with low concentrations of ARA but because of their similar properties separation of DGLA from ARA is difficult during PUFA purification [22]. Previous work on metabolic engineering of long chain-polyunsaturated fatty acid biosynthetic pathway was done in Saccharomyces cerevisiae and Aspergillus oryzae for DGLA production but its concentration was low (less than $3 \%$ ) $[1,11]$. Our recombinant $M$. circinelloides CBS277.49 showed superior advantages as it produce higher DGLA (5.72\%).

In most oleaginous microorganisms, nitrogen $(\mathrm{N})$ deficiency is a common strategy to trigger lipid accumulation. The amount of lipid increases under $\mathrm{N}$ starvation and lipid accumulation is often investigated by comparing the $\mathrm{N}$ rich phase to $\mathrm{N}$ deficiency phase in the entire bioprocess [23-25]. The maximum concentration of TFAs is $15 \%$ in CBS 277.49 [7]. Similar trends and results were observed in our experiments. Manipulation of the expression of $D 6 E$ genes had no significant effect on the growth and total lipid content (Fig. 2).

RT-qPCR results revealed that $D 6 E$ mRNA were maintained at elevated levels throughout the whole culture time of Mc-D6E and fatty acid analysis showed the presence of DGLA. These results confirmed that D6E was 
overexpressed in the recombinant strains and the mRNA of the genes encoding D6E was increased upon $\mathrm{N}$ deficiency. In M. circinelloides the major fatty acids are 16:0, 18:0, 18:1, 18:2 (LA) and 18:3 (GLA) [7, 8]. After overexpressing $D 6 E$ gene the same fatty acids were found as the major lipids and its expression did not affect the major lipid profile of this organism.

Researches has confirmed that deficiency of DGLA has been associated with various physiologic and pathophysiologic conditions including aging, diabetes, alcoholism, atopic dermatitis, premenstrual syndrome, rheumatoid arthritis, cancer and cardiovascular disease [26]. But the lack of sources for large scale production has prevented its scientific research and, as a result, its neutraceutical or pharmaceutical use. DGLA normally occurs only as an intermediate in the biosynthesis of ARA in higher plants or fungi and algae; it is not significantly accumulated in any organism. Instead, GLA-rich oils from several plant species are utilized as a DGLA precursor. Under certain conditions (e.g., calcium deficiency) the conversion of GLA to DGLA in the body is significantly diminished and GLA cannot replace DGLA. So the administration of DGLA is assumed to be more effective than the administration of GLA [27]. In our recombinant $M$. circinelloides DGLA is the only 20 carbon fatty acid that can be purified easily from other PUFA. Thus, the Mc-D6E may represent a promising source of DGLA for further upscaling and optimization of its industrial cultivation.

In summary, we successfully constructed a DGLA-producer $M$. circinelloides CBS277.49 by D6E (GLELO) gene overexpression. To the best of our knowledge, this is the first study to report the construction of DGLA-producing transformant using the successful gene cloning and recombination system in Mucor. The DGLA producer may have applications in industrial DGLA production. This work established a new scope for further research for improved production of DGLA in M. circinelloides, specifically in its high lipid-producing strain, WJ11.

\section{Methods}

\section{Strains, plasmids and culture conditions}

Mortierella alpina ATCC 32222 was used as the source of $D 6 E$ (GLELO) gene. The uracil auxotroph strain, pleuMU402 of M. circinelloides CB277.49 [28] was used as the recipient strains in transformation experiments to overexpress the elongase gene. Escherichia coli strain Top 10 was used for all cloning experiments and grown in lysogeny broth at $37{ }^{\circ} \mathrm{C}$. Plasmids pMAT1552 [29] were used as the cloning and expression vectors. Mortierella alpina ATCC 32222 was grown in 11 flask containing Potato Dextrose Water (PDW) for $72 \mathrm{~h}$ for mycelia collection. The recombinant strains Mc-D6E (D6E overexpresssion strains) and Mc-1552 (strains carrying the vector pMAT1552) as the control were initially cultivated in $1 \mathrm{l}$ flasks having $150 \mathrm{ml} \mathrm{K}$ \& R medium containing $30 \mathrm{~g} / 1$ glucose, $3.3 \mathrm{~g} / 1$ diammonium tartrate, $7.0 \mathrm{~g} / 1$ $\mathrm{KH}_{2} \mathrm{PO}_{4}, 2.0 \mathrm{~g} / 1 \mathrm{Na}_{2} \mathrm{HPO}_{4}, 1.5 \mathrm{~g} / 1 \mathrm{MgSO}_{4} \cdot 7 \mathrm{H}_{2} 0,1.5 \mathrm{~g} / 1$ yeast extract, $0.1 \mathrm{~g} / \mathrm{l} \mathrm{CaCl}{ }_{2} \cdot 2 \mathrm{H}_{2} 0,8 \mathrm{mg} / \mathrm{FeCl}_{3} \cdot 6 \mathrm{H}_{2} \mathrm{O}$, $1 \mathrm{mg} / \mathrm{l} \mathrm{ZnSO}{ }_{4} \cdot 7 \mathrm{H}_{2} 0,0.1 \mathrm{mg} / \mathrm{l} \mathrm{CuSO}_{4} \cdot 5 \mathrm{H}_{2} 0,0.1 \mathrm{mg} / \mathrm{l}$ $\mathrm{Co}\left(\mathrm{NO}_{3}\right)_{2} \cdot 6 \mathrm{H}_{2} 0$ and $0.1 \mathrm{mg} / \mathrm{l} \mathrm{MnSO}{ }_{4} \cdot 5 \mathrm{H}_{2} 0$, pH 6.0 [30] for $24 \mathrm{~h}$ at $30{ }^{\circ} \mathrm{C}$ with shaking at $150 \mathrm{rpm}$ and then inoculated at $10 \%(\mathrm{v} / \mathrm{v})$ into a 21 fermenter (BioFlo/CelliGen115, New Brunswick Scientific, Edison, NJ, USA) containing $1.51 \mathrm{~K} \& \mathrm{R}$ medium modified to contain $80 \mathrm{~g}$ glucose/l. Fermenters were held at $28{ }^{\circ} \mathrm{C}$, stirred at $700 \mathrm{rpm}$, with aeration at $0.5 \mathrm{vvm}$. The $\mathrm{pH}$ was maintained at 6.0 by automatic addition of $2 \mathrm{M} \mathrm{NaOH}$ for CBS277.49.

\section{Plasmid construction and the cloning strategy}

Plasmid, pMAT1552, that contains the $M$. circinelloides pyrG gene surrounded by up- and down-stream $1 \mathrm{~kb}$ of $\operatorname{carB-carRP}$ sequences, was used for construction of $D 6 E$ (GLELO) overexpressing plasmids for pleu-MU402. The pyrG encodes orotidine 5'-phosphate decarboxylase which produce uridine as a selectable marker and flanking sequences corresponding to regions surrounding the carotenogenic carRP-carRP gene allows its chromosomal integration by homologous recombination $[8,29]$. The D6E (GLELO) gene was isolated by PCR amplification from the genome of Mortierella alpina ATCC 32222 with corresponding primers GLELO-F/R (Additional file 1: Table S1). The primers contain 30 bp homologous sequences of both sides of XhoI restriction site in pMAT1552. After digestion the plasmid with XhoI, The PCR fragment was ligated into this site to generate plasmid as pMAT1552-GLELO for mutant pleu-MU402 (One step cloning kit, Takara). During experiment of gene cloning the ligation mixture was used to transform into chemically competent $E$. coli Top 10 cells. The plasmids isolated from these transformants were verified by doing PCR and the gene sequences were confirmed by DNA sequencing. The cloning strategy with the complete map of PMAT1552 and pMAT1552-GLELO were presented in Fig. 4.

\section{Transformation method}

The electroporation-mediated transformation was done according to the procedure described by Gutiérrez et al. [31] with little modification. Fresh Spores (no more than 1 week old) from uracil auxotroph strain, pleu-MU402 of M. circinelloides CB277.49 were collected and $12.5 \times 10^{7}$ spores were inoculated into $25 \mathrm{ml}$ ( $250 \mathrm{ml}$ flask) of the medium YPG plus uridine. After maintaining at $4{ }^{\circ} \mathrm{C}$ overnight without shaking, the solution was incubated at $28{ }^{\circ} \mathrm{C}$ and $200 \mathrm{rpm}$ in a rotary shaker for spore 

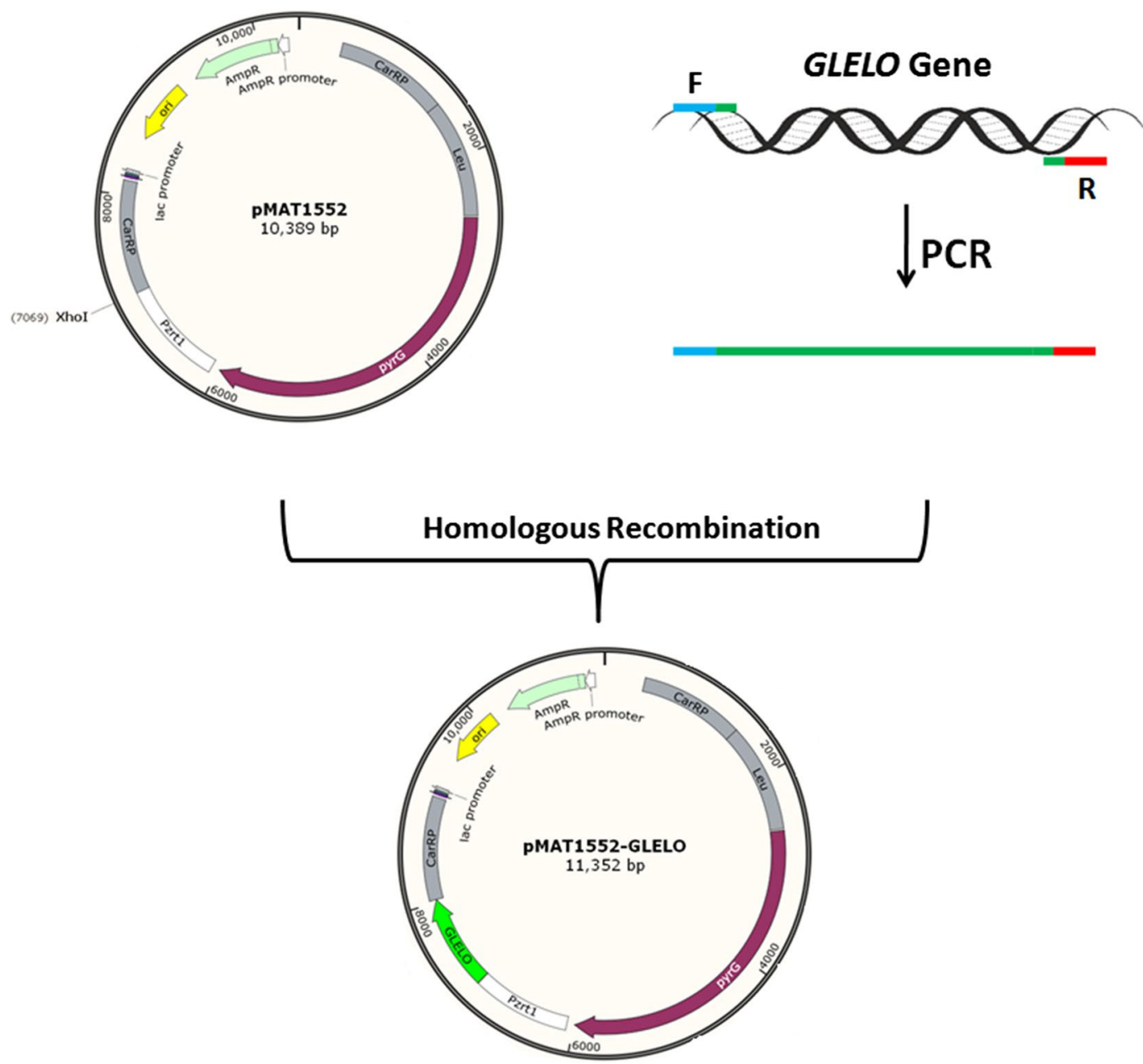

Fig. 4 Structure of plasmids pMAT1552 and pMAT1552-GLELO are shown. The D6E (GLELO) gene was isolated by PCR amplification with appropriate primers. The PCR fragment was ligated into Xhol restriction site to generate plasmid as pMAT1552-GLELO

germination (3.5 to $4 \mathrm{~h}$ ). Germinated spores were recovered by centrifugation at $1100 \mathrm{rpm}$ for $5 \mathrm{~min}$ at room temperature and washed with $5 \mathrm{ml}$ of PS $(0.01 \mathrm{M}$ sodium phosphate buffer $\mathrm{pH} 6.5$; $0.5 \mathrm{M}$ sorbitol) by centrifugation at $1750 \mathrm{rpm}$ for $5 \mathrm{~min}$ at room temperature.

To digest the cell wall, germinated spores were resuspended in $5 \mathrm{ml}$ of PS treated with $0.3 \mu$ l chitosanase RD (C0794, Sigma-Aldrich) and $1 \mathrm{mg} / \mathrm{ml}$ lysing enzymes (L-1412; Sigma-Aldrich) at $30{ }^{\circ} \mathrm{C}$ with gentle shaking $(60 \mathrm{rpm})$ for $90 \mathrm{~min}$. From this step the cells were handled with extreme care. Cell wall removal was monitored by following the loss of cell wall-associated refringence in protoplasts using a phase-contrast microscope. To stop the cell wall digestion, $10 \mathrm{ml}$ of ice cold $0.5 \mathrm{M}$ sorbitol was added. The protoplasts were recovered by centrifugation at $4{ }^{\circ} \mathrm{C}$ and $1100 \mathrm{rpm}$ for $5 \mathrm{~min}$, resuspended in $5 \mathrm{ml}$ of $0.5 \mathrm{M}$ cold sorbitol and centrifuged again in the same conditions. Finally a volume of $800 \mu \mathrm{l}$ of $0.5 \mathrm{M}$ sorbitol was added to these protoplasts and these were used for electroporation and allows for eight different transformation experiments.

For electroporation, $1 \mu \mathrm{g}$ of circular plasmid in a volume of $10 \mu \mathrm{l}$ were added to $100 \mu \mathrm{l}$ of protoplasts and the mixture was transferred to a $2 \mathrm{~mm}$ electroporation cuvette. An electrical pulse was applied to these cuvettes individually using the following conditions: field strength of $0.8 \mathrm{kV}$, capacitance of $25 \mu \mathrm{F}$, and constant resistance of $400 \Omega$. After applying an electrical pulse, $1 \mathrm{ml}$ of cold YPG medium containing $0.5 \mathrm{M}$ sorbitol was added to the electroporation cuvette immediately and the solution was transferred to a $1.5 \mathrm{ml}$ eppendorf tube. After incubation for $1 \mathrm{~h}$ at $26^{\circ} \mathrm{C}$ and $100 \mathrm{rpm}$, protoplasts were recovered by centrifugation at $1100 \mathrm{rpm}$ for $5 \mathrm{~min}$, resuspended in $500 \mu \mathrm{l}$ of YNB containing $0.5 \mathrm{M}$ sorbitol, and spread on selective medium plates (MMC plus $0.5 \mathrm{M}$ sorbitol) and incubated in the dark at $28{ }^{\circ} \mathrm{C}$ for 3 to 4 days. 
Determination of glucose and nitrogen in culture medium Glucose concentration in the culture was measured using a glucose oxidase Perid-test kit according to the manufacturer's instructions (Shanghai Rongsheng Biotech Co., Ltd.). Ammonium was assayed by the indophenol method [32].

\section{Determination of cell dry weight, total fatty acid and fatty acid analysis}

Biomass was harvested on a weighed filter paper by filtration through a Buchner funnel under reduced pressure and washed three times with distilled water, frozen overnight at $-80{ }^{\circ} \mathrm{C}$ and then freeze-dried. The weight of the biomass was determined gravimetrically. Biomass was collected by filtration and dried by lyophilize. The weight of empty fatty acid extraction tube was taken. $20 \mathrm{mg}$ dry weight was taken for cell fatty acids extraction. The total fatty acids were extracted with chloroform/methanol $(2: 1, \mathrm{v} / \mathrm{v})$ and weight of tube with fatty acid was taken. Total fatty acid was determined using following equation:

$$
\text { Total FA }=\frac{\mathrm{T} 1-\mathrm{T} 0}{\mathrm{Wm}} \times 100
$$

Here, $\mathrm{T}_{1}=$ Weight of tube with fatty acid, $\mathrm{T}_{0}=$ Weight of empty tube, $\mathrm{Wm}=$ Weight of mycelia.

For fatty acid analysis $10 \mathrm{mg}$ of dry mycellia was taken. Fatty acid was extracted by same method and methylated with $10 \%(\mathrm{v} / \mathrm{v})$ methanolic $\mathrm{HCl}$ at $60{ }^{\circ} \mathrm{C}$ for $3 \mathrm{~h}$. Pentadecanoic acid (15:0) was added into the freeze-dried cells as an internal standard. The resultant fatty acid methyl esters were extracted with n-hexane and were analyzed by GC equipped with a $30 \mathrm{~m} \times 0.32 \mathrm{~mm}$ DB-Waxetr column with $0.25 \mu \mathrm{m}$ film thickness. The program was as follows: $120^{\circ} \mathrm{C}$ for $3 \mathrm{~min}$, ramp to $200{ }^{\circ} \mathrm{C}$ at $5^{\circ} \mathrm{C}$ per min, ramp to $220^{\circ} \mathrm{C}$ at $4{ }^{\circ} \mathrm{C}$ per min, hold $2 \mathrm{~min}$.

\section{Gene expression and RT-qPCR analysis}

For reverse transcription-quantitative PCR (RT-qPCR) analysis, strains were grown in a 21 fermenter with $K$ \& $R$ medium, and the mycelium was harvested at 24,48 , and 72 h. Total RNA of $M$. circinelloides was extracted with Trizol after grinding under liquid $\mathrm{N}_{2}$ and reverse-transcribed using the Prime ScriptRT reagent kit (Takara) according to the manufacturer's instructions. RT-qPCR was performed using primers GLqPCR-F/R (Additional file 1: Table S1) on LightCycler 96 Instrument (Roche Diagnostics GmbH, Switzerland) with FastStart Universal SYBR Green Master (ROX) Supermix (Roche) according to the manufacturer's instruction. The mRNA expression level was normalized to levels of $18 \mathrm{~S}$ rRNA, and the results were expressed as relative expression levels. The data were quantified by the method of $2^{-\Delta \Delta C t}$.

\section{Statistical analysis}

A statistical analysis was carried out using SPSS 16.0 for Windows (SPSS Inc. Chicago, IL). The mean values and the standard error of the mean were calculated from the data obtained from three independent experiments. The differences between the means of the test were evaluated by Student's $t$ test, and $P<0.05$ was considered as significantly different.

\section{Additional file}

Additional file 1: Table S1. Primer sequences used in this study.

\section{Abbreviations}

OA: oleic acid; LA: linoleic acid; GLA: gamma linolenic acid; DGLA: dihomogamma linolenic acid; ARA: arachidonic acid; EPA: eicosapentaenoic acid; DPA: docosapentaenoic acid; DHA: docosahexaenoic acid; GLELO: gamma linolenic acid elongase; D6E: delta-6 elongase; PUFA: polyunsaturated fatty acid; GC: gas chromatography; VLCPUFA: very-long-chain polyunsaturated fatty acid; CDW: cell dry weight; SAFA: saturated fatty acids; MUFA: mono-unsaturated fatty acids; EFAs: essential fatty acids.

\section{Authors' contributions}

MAKK and JY performed the experimental design and experiments, computational analysis, fermentation testing, manuscript writing, figures and tables arrangement. SAH and $\mathrm{HZ}$ were involved in the experimental design. $\mathrm{LL}$ improved the figures and reviewed the manuscript. VG provided the tools for genetic engineering, performed results interpretation and review of final draft. YS proposed the project, and involved in result interpretation and review of the final draft. All authors read and approved the final manuscript.

\section{Author details}

${ }^{1}$ Colin Ratledge Center for Microbial Lipids, School of Agricultural Engineering and Food Science, Shandong University of Technology, Zibo 255000, Shandong, People's Republic of China. ${ }^{2}$ Departmento de Genética y Microbiología (Unidad Asociada al Instituto de Química Física Rocasolano, Consejo Superior de Investigaciones Científicas), Facultad de Biología, Universidad de Murcia, 30100 Murcia, Spain. ${ }^{3}$ State Key Laboratory of Food Science and Technology, School of Food Science and Technology, Jiangnan University, Wuxi 21412 , Jiangsu, China.

\section{Acknowledgements}

We would like to thank Mohamed Yusuf Bin Mohamed Nazir and Muhammad Hafiy Bin Mohd Halim for their assistance to draw pictures and data analysis.

\section{Competing interests}

The authors declare no competing or conflicts of interests in relation to the publication of this study. The authors have full control of all of the primary data and agree to allow the journal to review the data if needed.

Availability of data and materials

All data generated or analyzed during this study are included in this published article [and its Additional file].

\section{Consent for publication \\ Not applicable.}

\section{Ethics approval and consent to participate}

This article does not contain any studies with human participants or animals performed by any of the authors. 


\section{Funding}

This work was supported by the National Natural Science Foundation of China (No. 31670064), Natural Science Foundation of Shandong province (ZR2018BC058), Science and Technology Project of Shandong College (No. J16LE20 and J17KA133), Taishan Industry Leading Talent Project, and starting grant from Shandong University of Technology.

\section{Publisher's Note}

Springer Nature remains neutral with regard to jurisdictional claims in published maps and institutional affiliations.

Received: 31 October 2018 Accepted: 20 March 2019

Published online: 03 April 2019

\section{References}

1. Yazawa H, Iwahashi H, Kamisaka Y, Kimura K, Aki T, Ono K, Uemura H. Heterologous production of dihomo- $y$-linolenic acid in Saccharomyces cerevisiae. Appl Environ Microbiol. 2007;73(21):6965-71. https://doi. org/10.1128/AEM.01008-07.

2. Simopoulos AP. Essential fatty acids in health and chronic disease. Am J Clin Nutr. 1999;70:560S-9S.

3. Wang $\mathrm{M}$, Chen J, Zhang $\mathrm{H}$, Song Y. Molecular switch that controls the flux of linolenic acid into n- 6 or $n-3$ polyunsaturated fatty acids in microorganisms. Am J Biochem Biotechnol. 2014;10(2):105-15.

4. Das UN. Essential fatty acids: biochemistry, physiology and pathology. Biotechnol J. 2006;1(4):420-39.

5. Tomaro ML, Frydman J, Frydman RB. Heme oxygenase induction by $\mathrm{CoCl} 2$, Co-protoporphyrin IX, phenylhydrazine, and diamide: evidence for oxidative stress involvement. Arch Biochem Biophys. 1991;286(2):610-7.

6. Das UN. Essential fatty acids and their metabolites could function as endogenous HMG-CoA reductase and ACE enzyme inhibitors, antiarrhythmic, anti-hypertensive, anti-atherosclerotic, anti-inflammatory, cytoprotective, and cardioprotective molecules. Lipids Health Dis. 2008;7:37.

7. Tang X, Zan X, Zhao L, Chen H, Chen YQ, Chen W, Song Y, Ratledge C. Proteomics analysis of high lipid-producing strain Mucor circinelloides WJ11: an explanation for the mechanism of lipid accumulation at the proteomic level. Microb Cell Fact. 2016;15:35

8. Zhang Y, Luan X, Zhang H, Garre V, Song Y, Ratledge C. Improved $Y$-linolenic acid production in Mucor circinelloides by homologous overexpressing of delta-12 and delta- 6 desaturases. Microb Cell Fact. 2017;16:113.

9. Yang J, Li S, Khan MA, Garre V, Vongsangnak W, Song Y. Increased lipid accumulation in Mucor circinelloides by overexpression of mitochondrial citrate transporter genes. Ind Eng Chem Res. 2019;58:2125-34. https:// doi.org/10.1021/acs.iecr.8b05564.

10. Hussain SA, Hameed A, Khan M, Kabir A, Zhang Y, Zhang H, Garre V, Song Y. Engineering of fatty acid synthases (FASs) to boost the production of medium-chain fatty acids (MCFAs) in Mucor circinelloides. Int J Mol Sci. 2019;20:786. https://doi.org/10.3390/ijms20030786.

11. Chutrakul C, Jeennor S, Panchanawaporn S, Cheawchanlertfa P, Suttiwattanakul S, Veerana M, Laoteng K. Metabolic engineering of long chainpolyunsaturated fatty acid biosynthetic pathway in oleaginous fungus for dihomo-gamma linolenic acid production. J Biotechnol. 2016;20(218):8593. https://doi.org/10.1016/j.jbiotec.2015.12.003 (Epub 2015 Dec 10)

12. Kikukawa H, Sakuradani E, Ando A, Okuda T, Shimizu S, Ogawa J. Microbial production of dihomo- $\gamma$-linolenic acid by $\Delta 5$-desaturase gene-disruptants of Mortierella alpina 1S-4. J Biosci Bioeng. 2016;122(1):22-6. https:// doi.org/10.1016/j.jbiosc.2015.12.007.

13. Bajpai PK, Bajpai P, Ward OP. arachidonic acid production by fungi. Appl Environ Microbiol. 1991;57:1255-8.

14. Ratledge C, Wynn JP. The biochemistry and molecular biology of lipid accumulation in oleaginous microorganisms. Adv Appl Microbiol. 2002;51:1-51.
15. Jang HD, Lin YY, Yang SS. Effect of culture media and conditions on polyunsaturated fatty acids production by Mortierella alpina. Bioresour Technol. 2005;96:1633-44.

16. Ratledge C. Fatty acid biosynthesis in microorganisms being used for single cell oil production. Biochimie. 2004;86:807-15.

17. Wang $H$, Chen $H, H$ G, Yang B, Feng $Y$, Wang $Y$, Feng $L$, Zhao J, Song $Y$, Zhang $H$, Chen YQ, Wang L, Chen W. Role of the phenylalanine-hydroxylating system in aromatic substance degradation and lipid metabolism in the oleaginous fungus Mortierella alpina. Appl Environ Microbiol. 2013;79(10):3225-33

18. Takeno S, Sakuradani E, Murata S, Inohara-Ochiai M, Kawashima H, Ashikari T, Shimizu S. Molecular evidence that the rate-limiting step for the biosynthesis of arachidonic acid in Mortierella alpina is at the level of an elongase. Lipids. 2005;40(1):25-30.

19. Rodríguez-Frómeta RA, Gutiérrez A, Torres-Martínez S, Garre V. Malic enzyme activity is not the only bottleneck for lipid accumulation in the oleaginous fungus Mucor circinelloides. Appl Microbiol Biotechnol. 2013;97:3063-72.

20. Tavares S, Grotkjær T, Obsen T, Haslam RP, Napier JA, Gunnarsson N. Metabolic engineering of Saccharomyces cerevisiae for production of eicosapentanoic acid, using a novel $\Delta 5$-desaturase from Paramecium tetraurelia. Appl Environ Microbiol. 2011. https://doi.org/10.1128/aem.01935-10.

21. Sakuradani E, Murata S, Kanamaru H, Shimizu S. Functional analysis of a fatty acid elongase from arachidonic acid-producing Mortierella alpina 1S-4. Appl Microbiol Biotechnol. 2008:81:497-503.

22. Jareonkitmongkol S, Sakuradani E, Shimizu S. A novel delta5-desaturasedefective mutant of Mortierella alpina 1S-4 and Its dihomo-gammalinolenic acid productivity. Appl Environ Microbiol. 1993;59(12):4300-4.

23. Wynn JP, bin Abdul Hamid A, Ratledge C. The role of malic enzyme in the regulation of lipid accumulation in filamentous fungi. Microbiology. 1999;145:1911-7.

24. Yang ZK, Ma YH, Zheng JW, Yang WD, Liu JS, Li HY. Proteomics to reveal metabolic network shifts towards lipid accumulation following nitrogen deprivation in the diatom Phaeodactylum tricornutum. J Appl Phycol. 2014:26:73-82.

25. Chen H, Hao G, Wang L, Wang H, Gu Z, Liu L, Zhang H, Chen W, Chen YQ. Identification of a critical determinant that enables efficient fatty acid synthesis in oleaginous fungi. Sci Rep. 2015;5:11247.

26. Wang $X$, Lin H, Yan G. Multiple roles of dihomo-g-linolenic acid against proliferation diseases. Lipids in Health and Disease. 2012;11:25.

27. Iskandarov U, Khozin-Goldberg I, Cohen Z. Selection of a DGLA-producing mutant of the microalga Parietochloris incisa: I. identification of mutation site and expression of VLC-PUFA biosynthesis genes. Appl Microbiol Biotechnol. 2011;90(249-256):34.

28. Nicolas FE, de Haro JP, Torres-Martinez S, Ruiz-Vazquez RM. Mutants defective in a Mucor circinelloides dicer-like gene are not compromised in siRNA silencing but display developmental defects. Fungal Genet Biol. 2007;44(6):504-16.

29. Roncero MI, Jepsen LP, Stroman P, van Heeswijck R. Characterization of a leuA gene and an ARS element from Mucor circinelloides. Gene. 1989;84(2):335-43.

30. Kendrick A, Ratledge C. Desaturation of polyunsaturated fatty acids in Mucor circinelloides and the involvement of a novel membrane-bound malic enzyme. Eur J Biochem. 1992;209(2):667-73.

31. Gutiérrez A, López-García S, Garre V. High reliability transformation of the basal fungus Mucor circinelloides by electroporation. J Microbiol Methods. 2011:84:442-6.

32. Chaney AL, Marbach EP. Modified reagents for determination of urea and ammonia. Clin Chem. 1962:8:130-2. 